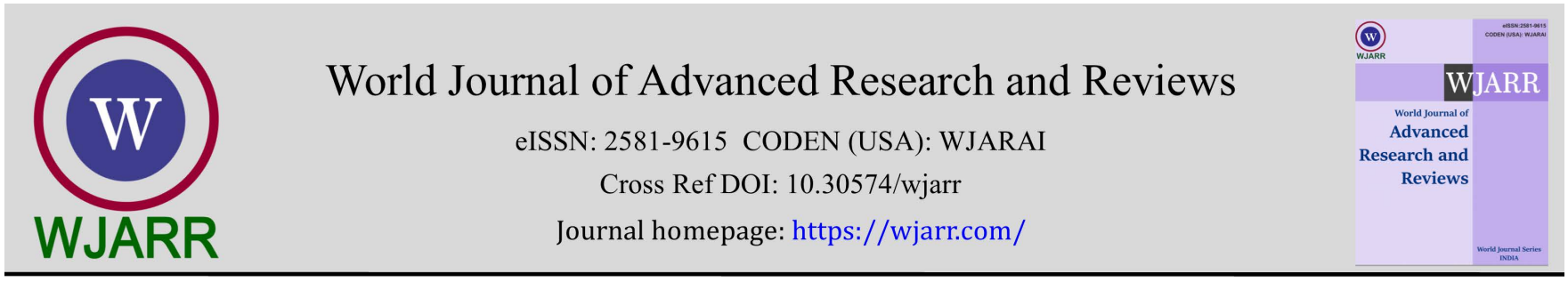

(CASE REPORT)

Check for updates

\title{
An unusual presentation of "Mirror-Image" bilateral giant carotid cavernous aneurysms: Case report and review of the literature
}

\author{
Yao Christian Hugues Dokponou 1, 2, *, Mamoune El Mostarchid 1, 2, Housni Abderrahmane 1, 2, Zakaria \\ Chandide Tlemcani 1,2, Abad Cherif El Asri 1,2 and Miloudi Gazzaz 1,2 \\ ${ }^{1}$ Department of Neurosurgery, Mohammed V Military Teaching Hospital Rabat. \\ 2 Mohammed V University, Faculty of Medicine and Pharmacy, Rabat Morocco.
}

World Journal of Advanced Research and Reviews, 2021, 12(02), 544-548

Publication history: Received on 17 October 2021; revised on 22 November 2021; accepted on 24 November 2021

Article DOI: https://doi.org/10.30574/wjarr.2021.12.2.0627

\begin{abstract}
The almost asymptomatic "mirror-image" bilateral giant intracavernous carotid artery aneurysms are not common and its successful conservative management without further neurological complications is rarely reported.

We report a case of a 64-year-old woman, admitted with a rapidly progressive headache, with no other signs or symptoms associated. The Head CT-Scan shows bilateral parasellar round hyperdense lesions and the Magnetic resonance angiography discloses bilateral giant intracavernous carotid artery aneurysms in detail. The clinical presentation of these types of lesions depends on their mass effect on the surrounding neurovascular structures. So, possibly no mass effect on any structure, then no obvious expected symptoms. A patient with these conditions and without neurological deficit should not be rushed to surgery or endovascular treatment.
\end{abstract}

Keywords: Carotid cavernous aneurysms; Mirror-image; Conservative treatment; Case report

\section{Introduction}

Unruptured mirror aneurysms are paired aneurysms found within similar distributions on bilateral intracranial arteries. Internal carotid aneurysms in its intracavernous segment represent approximately 3-5\% of all intracranial aneurysms and $15 \%$ of those originated in the internal carotid. Pain and neuro-ophthalmologic deficits due to neurovascular compression are frequent, which highlights the possibility of surgical treatment [1]. Meanwhile, some others that are not symptomatic, can be managed without surgery. This atypical type of presentation of the carotidcavernous aneurysm is most probably due to the anatomical variation of the internal carotid artery and the preferred site of the appearance of the aneurysms at carotid siphon segments (Fig 1). Compressive phenomena are subject to the direction of the expansion of the aneurysmal sac. Anterior growth can produce superior orbital fissure syndrome; posterolateral growth may erode into the petrous bone and cause hypoacusia or hemorrhagic otitis; medial growth, by compressing the pituitary stalk, can result in disinhibition of prolactin secretion; finally, lateral growth may lead to a cavernous sinus syndrome [2]. This is why some carotid-cavernous aneurysms may be asymptomatic or presented only with a headache because the aneurysmal sac did not expand toward any of those four previously cited directions. we present a rare case of "mirror-image" bilateral giant carotid cavernous aneurysms revealed by atypical signs and symptoms and we reviewed the literature about previous cases, with particular reference to clinical presentation, neuroradiological findings, treatment, and outcome (Table 1).

\footnotetext{
* Corresponding author: Yao Christian Hugues Dokponou

Department of Neurosurgery, Mohammed V Military Teaching Hospital Rabat.

Copyright (C) 2021 Author(s) retain the copyright of this article. This article is published under the terms of the Creative Commons Attribution Liscense 4.0.
} 


\section{Case report}

A 64-year-old woman, a housewife, was admitted for rapidly progressive headache, no other signs or symptoms associated. Only headache with unremarkable past medical history. Neurological examination was apparently normal. The head CT-Scan found two separate lesions, round in shape, spontaneously hyperdense located at the right and left cavernous sinuses with intrasellar extension and were highly enhanced by the injection of iodine solution. These lesions measure $23.2 \times 22.9 \mathrm{~mm}$ on the right and $19.4 \times 16.5 \mathrm{~mm}$ on the left. The lesions englobe on both sides of the carotid siphon with respect to the oculo-motor muscles as well as to the optic sheath (Fig 2/A \& B). Two possible diagnoses were made out of these characteristics: Intra-cavernous meningiomas or aneurysms of carotid siphon. The Magnetic resonance angiography was done and confirmed the lesion to be Bilateral Giant Carotid Cavernous Aneurysms (Fig 2/C \& D).

The patient was still neurologically stable, the headache was successfully managed by painkillers, and she was followed up for two years without any other clinical manifestation. But at this time, she was a bit depressive, and not willing to continue coming for check-ups, and refuses any further investigation and management.

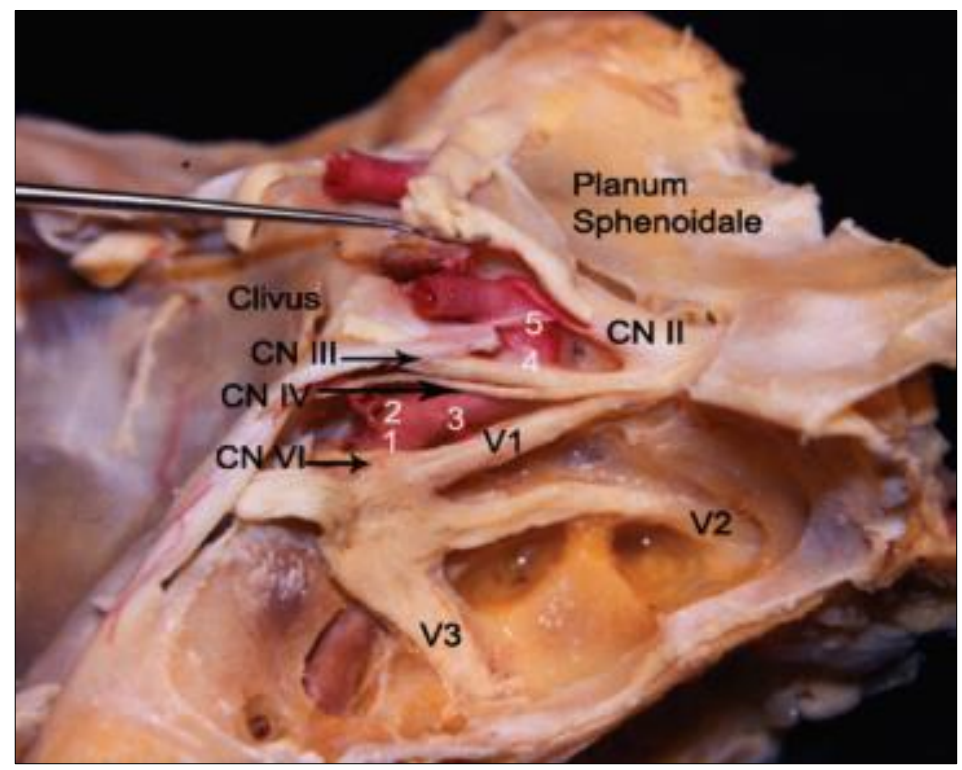

Figure 1 Cavernous sinus dissection, demonstrating cranial nerves: II-III-IV-V1-V2-V3-VI; 1, the posterior vertical segment; 2 , the posterior bend; 3 , the horizontal segment; 4 , the anterior bend; 5 , the anterior vertical segment (By Castro JAF, MD)

Table 1 Patient characteristics of Giant Bilateral Carotid Cavernous Aneurysm (GBCCA) in the Literature

\begin{tabular}{|c|c|c|c|c|c|c|c|}
\hline $\begin{array}{l}\text { First } \\
\text { author }\end{array}$ & Year & Sex & $\begin{array}{c}\text { Age } \\
\text { (years) }\end{array}$ & $\begin{array}{c}\text { Clinical } \\
\text { presentation }\end{array}$ & $\begin{array}{l}\text { Neuroradiological } \\
\text { findings }\end{array}$ & Treatment & Outcome \\
\hline Faria [13] & 1989 & $\mathrm{~F}$ & 41 & Diplopia & Bilateral GBCCA & $\begin{array}{l}\text { Left and right } \\
\text { carotid } \\
\text { ligation and } \\
\text { occlusion }\end{array}$ & $\begin{array}{l}\text { Recovery } \\
\text { (slight right } \\
\text { ptosis and a } \\
\text { limitation of } \\
\text { vertical gaze) }\end{array}$ \\
\hline $\begin{array}{l}\text { Winter } \\
\text { [14] }\end{array}$ & 1989 & M & 16 & Diplopia & Bilateral GBCCA & $\begin{array}{l}\text { Conservative } \\
\text { treatment }\end{array}$ & $\begin{array}{l}28 \text { months } \\
\text { follow-up, No } \\
\text { signs of } \\
\text { neurological } \\
\text { progression }\end{array}$ \\
\hline
\end{tabular}




\begin{tabular}{|c|c|c|c|l|l|l|l|}
\hline $\begin{array}{c}\text { Kopsachilis } \\
\text { [12] }\end{array}$ & 2013 & F & 26 & $\begin{array}{l}\text { Headache and } \\
\text { diplopia }\end{array}$ & Bilateral GBCCA & $\begin{array}{l}\text { Coil } \\
\text { embolization } \\
\text { at sides } \\
\text { both } \\
\text { with a } \\
\text { distance of 3 } \\
\text { months }\end{array}$ & $\begin{array}{l}\text { Complete } \\
\text { recovery }\end{array}$ \\
\hline $\begin{array}{c}\text { Berhouma } \\
\text { [15] }\end{array}$ & 2007 & F & 52 & $\begin{array}{l}\text { Right-sided } \\
\text { ptosis and } \\
\text { facial pain on } \\
\text { V1 territory }\end{array}$ & Bilateral GBCCA & $\begin{array}{l}\text { Patient } \\
\text { refused } \\
\text { surgery }\end{array}$ & Partial \\
recovery
\end{tabular}
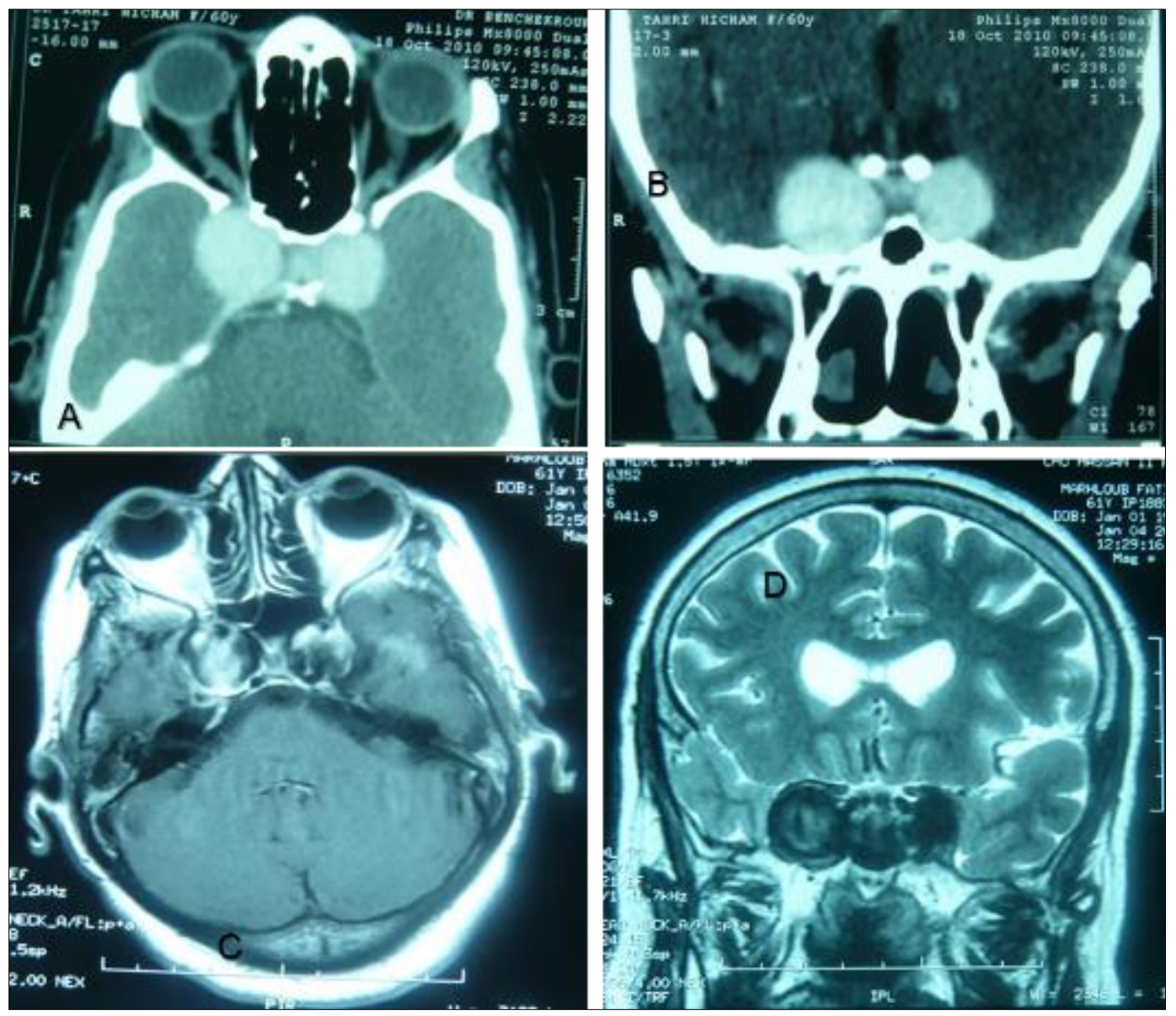

Figure 2 A \& B / Brain CT angiography showing giant bilateral carotid cavernous aneurysms measuring 23.2 X $22.9 \mathrm{~mm}$ on the right and 19.4 X $16.5 \mathrm{~mm}$ on the left; C \& D/ T1-weighted axial hyperintense and T2-weighted coronal hypointense lesions on brain magnetic resonance imaging confirming the presence of the giant bilateral carotid cavernous aneurysms 


\section{Discussion}

The decision to treat giant bilateral carotid cavernous aneurysms (GBCCA) always presents a challenge because treatment implies that the benefits of therapy outweigh the risks of intervention. According to the ISUIA (International Study on Unruptured Intracranial Aneurysm) data, the rupture risk of asymptomatic lesions $<13 \mathrm{~mm}$ in size is $\sim 0 \%$ rupture risk over 5 years, 13-24 mm in size harboring a 3\% rupture risk within 5 years and $>25 \mathrm{~mm}$ having a $6.4 \%$ rupture risk within 5 years $[3,4]$. Despite these estimates, the ISUIA data do not address symptomatic lesions or GBCCA with characteristics that predispose them to increased risk. As such, the decision to treat certain GBCCA has to depend on the lesion characteristics and/or the severity of the symptoms. As a result, the strategy of GBCCA management differs significantly from that of other intracranial aneurysms. Our patient aneurysmal characteristics fall in the 3\% rupture risk, meaning this patient can be followed up for at least 5 years as far as she stays asymptomatic. Nevertheless, the reasons for rupture are numerous, and rupture generally leads to carotid-cavernous fistula and, rarely, to subarachnoid hemorrhage.

The diagnosis is most time easily made following the classical clinical presentation depending on which neurovascular structures have been taken under the compression; from headache, diplopia, ptosis, to disturbances of the pituitary hormone production can be seen. For the asymptomatic patient like the one of our case reports, the lesions are most often discovered incidentally on intracranial imaging acquired during the work-up for unrelated conditions such as headache, closed-head trauma, or other nonspecific cranial, ocular, or facial complaints. The imaging modality for diagnosing a GBCCA is quite simple either with the CT-scan, CT Angiography, or MR Angiography. Despite the advancement of these radiological techniques, the current imaging limitations, due mainly to inadequate spatial resolution, do not permit the thicknesses of these cavernous structures to be determined, therefore making identification of exact anatomical relationships difficult at best [4-6]. Patients with cavernous carotid aneurysms were discussed in a joint meeting with neurologists, neurosurgeons, and neuroradiologists. Treatment was tailored to the individual patient, accounting for clinical presentation, patient age, comorbidity, and patient wishes. In patients with asymptomatic cavernous sinus aneurysms that were either incidentally discovered or added to another symptomatic aneurysm, treatment offer was dependent on several patients and aneurysm characteristics, such as patient age, comorbidity, aneurysm size, and aneurysm neck size. For small aneurysms with a small or intermediate neck size, coiling was the preferred treatment. For large and giant aneurysms, carotid artery occlusion was considered first. If test occlusion indicated nontolerance, either conservative therapy or bypass surgery was offered [7-9]. Patients with mirror aneurysms were more likely to be female, report a family history of aneurysmal subarachnoid hemorrhage (SAH), and have larger aneurysms, whereas mirror aneurysms did not differ from non-mirror aneurysms in terms of rupture rate or clinical risk factors including age, blood pressure, smoking history, or cardiac disease. The distribution on cavernous internal carotid artery counts only for $13 \%$ and its management is conservative in most cases $[10,11]$.

\section{Conclusion}

The giant bilateral carotid cavernous aneurysms are very rare, easy to diagnose with the current available neuroradiological tools but the choice of the management still remains controversial and depends on the lesion's characteristics as well as the patient comorbidities and clinical presentation. Nonetheless, conservative treatment is the main choice for the first 5 years as far as the patient remained asymptomatic.

\section{Compliance with ethical standards}

\section{Disclosure of conflict of interest}

The authors declare that they have no conflicts of interest.

\section{Statement of informed consent}

The patient gave his informed consent to publish his case.

\section{Authors' contributions}

Yao Christian Hugues Dokponou: Conceptualization, Writing original draft, \& editing. Mamoune El MOSTARCHID: Writing, review \& editing. Housni ABDERRAHMANE: Writing, review \& editing. Zakaria CHANDIDE TLEMCANI: Review \& editing. Abad Cherif EL ASRI: Review \& editing. Miloudi GAZZAZ: Supervision, Validation, \& review. 


\section{Funding}

The authors did not receive any funding for the preparation of this case report.

\section{References}

[1] Vasconcellos LP de, Flores JAC, Veiga JCE, Conti MLM, Shiozawa P. Presentation and treatment of carotid cavernous aneurysms. Arquivos de neuro-psiquiatria. 2008; 66(2A): 189-93.

[2] Díaz MB, Mercado FC, Plaghos LAL. "Mirror-Image" Bilateral Giants: Intracavernous Carotid Artery Aneurysms. Interv Neuroradiol [Internet]. 1 Sep 2006; 12(3): 251-6.

[3] Wiebers DO, Whisnant JP, Huston J, Meissner I, Brown RD, Piepgras DG, et al. Unruptured intracranial aneurysms: natural history, clinical outcome, and risks of surgical and endovascular treatment. Lancet. 2003 Jul 12; 362(9378): 103-10.

[4] Eddleman CS, Hurley MC, Bendok BR, Batjer HH. Cavernous carotid aneurysms: to treat or not to treat? Neurosurgical focus. 2009; 26(5): E4.

[5] Gagliardi D, Faravelli I, Villa L, Pero G, Cinnante C, Brusa R, Mauri E, Tresoldi L, Magri F, Govoni A, Bresolin N. Bilateral Cavernous Carotid Aneurysms: atypical presentation of a rare cause of mass effect. A case report and a review of the literature. Frontiers in neurology. 2018 Aug 2;9:619.

[6] Ambekar S, Madhugiri V, Sharma M, Cuellar H, Nanda A. Evolution of management strategies for cavernous carotid aneurysms: a review. World neurosurgery. 2014; 82(6): 1077-85.

[7] Rooij WJ van. Endovascular Treatment of Cavernous Sinus Aneurysms. American Journal of Neuroradiology [Internet]. 2012 Feb 1 [cited 2021 Jul 20]; 33(2): 323-6.

[8] Morón FE, Klucznik RP, Mawad ME, Strother CM. Endovascular treatment of high-flow carotid cavernous fistulas by stent-assisted coil placement. American Journal of Neuroradiology. 2005; 26(6): 1399-404.

[9] Iqbal M, Irfan S, Singh H, Ajay M, Singh D. Giant bilateral cavernous segment internal carotid artery aneurysms. Neurology India [Internet]. 2017 Jan 11 [cited 2021 Jul 20]; 65(6): 1430.

[10] Meissner I, Torner J, Huston J, Rajput ML, Wiebers DO, Jones LK, et al. Mirror aneurysms: a reflection on natural history: Clinical article. Journal of Neurosurgery [Internet]. 2012 Jun 1 [cited 2021 Jul 20]; 116(6): 1238-41.

[11] Lee YJ, Parreira T, Matouk CC, Menezes R, Mandell DM, terBrugge KG, et al. Clinical characteristics and preferential location of intracranial mirror aneurysms: a comparison with non-mirror multiple and single aneurysms. Neuroradiology [Internet]. 1 Jan 2015; 57(1): 35-40.

[12] Kopsachilis N, Pefkianaki M, Carifi G, Lialias I. Bilateral intracavernous carotid artery aneurysms presenting as diplopia in a young patient. Case reports in medicine. 2013 Jan 1;2013.

[13] Faria Jr MA, Fleischer AS, Spector RH. Bilateral giant intracavernous carotid aneurysms treated by bilateral carotid ligation. Surgical neurology. 1980 Sep 1;14(3):207-10.

[14] Winter RK, Hourihan MD, McKnight LG, Powell N. Bilateral giant intracavernous carotid aneurysms in a 16-yearold boy. Neuroradiology. 1989 Jul 1;31(3):284-6.

[15] Berhouma M, Chekili R, Jemel H, Khaldi M. A Foix's syndrome revealing “mirror"giant intracavernous aneurysms. An illustrative case report of a therapeutic dilemma. Acta neurologica belgica. 2007 Dec 1;107(4):122.

\section{Author's Short biography}

Dr. Dokponou Hugues is a major of Benin Armed Forces, had worked with the United Nations as a
Deputy Chief Medical Officer; currently undergoing postgraduate training in neurosurgery at the
Mohammed V Military Teaching Hospital of Rabat in Morocco. He is a peer reviewer for many
outstanding international journals and an Associate Editor at the Pan African Medical Journal. In
addition, he has published many scientific papers and co-authored different reviews in his field. He
is the Chairman of the Association of Benin \& Togo Aspiring Neurosurgeon.

